Article

\title{
The Inhibition of Serine/Threonine Protein Phosphatase Type 5 Mediates Cantharidin Toxicity to Control Periplaneta americana (L.)
}

\author{
Hong Sun ${ }^{\dagger}$, Yifan $\mathrm{Li}^{\dagger}$, Xinyu $\mathrm{Li}^{\dagger}$ and Yalin Zhang * \\ Key Laboratory of Plant Protection Resources \& Pest Management of the Ministry of Education, \\ College of Plant Protection, Northwest A\&F University, Yangling 712100, China; sunhong@nwafu.edu.cn (H.S.); \\ liyifanshr@nwafu.edu.cn (Y.L.); lixinyu8023@nwafu.edu.cn (X.L.) \\ * Correspondence: yalinzh@nwafu.edu.cn \\ + Co-first authors.
}

Received: 24 August 2020; Accepted: 5 October 2020; Published: 8 October 2020

check for updates

Simple Summary: The American cockroach, Periplaneta americana (L.), is a worldwide common sanitary pest. Controlling cockroaches mainly relies on chemical insecticides. However, the irrational and extensive use of insecticides has resulted in increasing resistance in cockroaches. Therefore, alternative agents are urgently needed. Cantharidin (CTD) is an insect defensive toxin that has a significant toxicity against a broad range of pests. In this study, we evaluated the bioactivity of CTD and its derivative Norcantharidin (NCTD) against P. americana to determine their potential for controlling P. americana. CTD showed a significant ingestion toxicity against P. americana $\left(\mathrm{LC}_{50}=50.9 \mu \mathrm{g} / \mathrm{mL}\right.$ ). To further explore the reason for the toxicity of CTD against P. americana, we cloned and expressed the serine/threonine protein phosphatase type 5 in P. americana (PaPP5) and performed inhibition assays of CTD and NCTD on serine/threonine protein phosphatases (PSPs) and PaPP5. The inhibition assays demonstrated that both CTD and NCTD had inhibitory effects on PSPs and PaPP5. The inhibitory capacity of CTD was superior to that of NCTD in both the PSPs and PP5 inhibition assays. These findings contribute to our understanding of CTD as a biorational pesticide to control P. americana and provide new insights into insecticide development using PP5 as a target.

\begin{abstract}
The American cockroach, Periplaneta americana (L.), is a notorious urban pest. It has developed insecticidal resistance to commonly used insecticides. Cantharidin (CTD) is a defensive toxin derived from blister beetles. It has been verified to have insecticidal toxicity in a range of pests. In this study, we determined the ingestion toxicity of CTD and norcantharidin (NCTD) to P. americana to test whether they had the potential to be effective against $P$. americana. Bioassays revealed that CTD produces toxicity against $P$. americana. The median lethal concentration $\left(\mathrm{LC}_{50}\right)$ value of CTD was $50.92 \mu \mathrm{g} / \mathrm{mL}$, while NCTD displayed nearly no toxicity against P. americana. The inhibition assays of serine/threonine protein phosphatases (PSPs) in P. americana indicated that CTD and NCTD could inhibit PSPs. The value of the half maximal inhibitory concentration $\left(\mathrm{IC}_{50}\right)$ of CTD was $7.21 \pm 0.94 \mu \mathrm{M}$, whereas that of NCTD was higher, at $31.65 \pm 3.87 \mu \mathrm{M}$. Furthermore, the inhibition effect of CTD on the serine/threonine protein phosphatase type 5 of P. americana (PaPP5) was superior to that of NCTD. Specifically, the $\mathrm{IC}_{50}$ of CTD reached $0.39 \pm 0.04 \mu \mathrm{M}$, while the $\mathrm{IC}_{50}$ of NCTD was $1.87 \pm 0.23 \mu \mathrm{M}$. This study paves the way for insect-derived agents (CTD) to be applied toward controlling P. americana and contributes to the development of novel insecticides based on PP5 as a target.
\end{abstract}

Keywords: Periplaneta americana; Cantharidin; serine/threonine protein phosphatase 


\section{Introduction}

The American cockroach, Periplaneta americana (L.), is a worldwide sanitary pest [1]. P. americana is of serious concern due to its ability to carry viruses, bacteria, and parasites [2]. It potentially contaminates food, thereby spreading disease and damaging public health [3]. This pest is difficult to control, since $P$. americana has both a strong reproduction capacity and survivability $[4,5]$. Currently, the control of cockroaches principally relies on chemical insecticides [6-8]. The nine classes of insecticides recommended by the WHO against cockroaches include carbamates, hydrazines, inorganics, insect growth regulators, neonicotinoids, organophosphates, pyrethroids, arylpyrazole, and sulfonamide $[9,10]$. However, previous reports have documented that cockroaches have developed resistance to some of these above-mentioned insecticides. For example, P. americana shows low levels of resistance against organophosphates and pyrethroids [11,12]. Therefore, the development of new agents is urgent in order to solve the insecticide resistance problem in controlling this cockroach.

Biopesticides have an edge over traditional chemical pesticides due to biopesticides being environmentally friendly and not prone to inducing resistance $[13,14]$. To date, many studies have reported botanical insecticides, such as essential oils, to have outstanding insecticidal activities. As reported, the Curcuma longa essential oil has been found to have an excellent insecticidal activity against Lucilia cuprina larvae, and a Carlina acaulis root essential oil has significant insecticidal activity against the housefly $[15,16]$. Meanwhile, research conducted to date shows that essential oils have effective contact, fumigation, and repellency activity against cockroaches [17,18]. In addition, the insecticidal activity of microbial agents and their metabolites on P. americana has also been extensively studied. Previous studies have shown that the application of mycoinsecticides for controlling P. americana has increased. Metarhizium anisopliae, Metarhizium robertsii, and Beauveria bassiana have been demonstrated to kill nymphs of $P$. americana $[19,20]$. However, little information is available on insect-derived pesticides for controlling cockroaches.

Cantharidin (CTD) comes from blister beetles, where it is a defensive toxin and protects blister beetles from attack [21,22]. More recently, its application in plant protection has attracted increasing attention. In the last century, there was a report indicating that CTD has the capacity to deter insects [23]. More recent reports indicate that CTD has contact, stomach, or repellent insecticidal toxicity against many pests, including Plutella xylostella (L.), Helicoverpa armigera (Hübner), Mythimna separate (Walker), Cydia pomonella (L.), and Musca domestica (L.) [24-30]. Meanwhile, CTD also shows antifungal activity [31]. Previous research has demonstrated that CTD is an inhibitor of serine/threonine protein phosphatases (PSPs), including PP1, PP2A, PP4, PP5, and PP6, and the inhibition rate can reach nanomolar (nM) levels [32-35]. In addition, researchers have demonstrated that CTD is capable of inhibiting PP5 of Plutella xylostella (L.) [36]. The results produced by computer simulation support PP5 being the target of CTD in P. xylostella (L.), inferring that the insecticidal mechanism of CTD results from the inhibition of target protein PP5 [37]. However, the natural CTD resource is limited, and artificial synthetic versions are difficult to produce [38,39]. Therefore, the development of CTD analogues is of importance for its expanded application. Norcantharidin (NCTD) is a representative derivative of CTD and has a similar structure and bioactivity, as well as the same target protein as CTD (PSPs) [40]. In agriculture, NCTD has been found to have both insecticidal activity and antifungal activity [41].

In this study, the ingestion toxicity of CTD and its derivative NCTD against P. americana was determined through bioassays. In addition, we cloned the PP5 gene and expressed the catalytic domain of PP5 (PP5c) from P. americana. The inhibition capacity of CTD and its analogues on the PSPs and PP5c of P. americana were tested. The results indicate that CTD had a better toxicity on P. americana and the inhibition effect on the target protein PP5c was significant. These findings support the potential of CTD as a biorational pesticide to be applied to control P. americana, and may illuminate the application of insect-derived agents in controlling P. americana. 


\section{Materials and Methods}

\subsection{Periplaneta americana Strain}

A susceptible P. americana strain without prior exposure to any insecticides or CTD was maintained in a glass chamber $(80 \times 32 \times 30 \mathrm{~cm})$ with sawdust in the bottom to maintain moisture. The glass chamber was smeared with Vaseline to prevent the P. americana from escaping. The rearing conditions were kept at $27 \pm 2{ }^{\circ} \mathrm{C}$, with a $65 \pm 5 \%$ relative humidity and a photoperiod of $12: 12 \mathrm{~h}(\mathrm{~L}: \mathrm{D})$. Breadcrumbs, milk powder, fresh apples, and water were supplied for P. americana. Healthy nymphs (emerging for 1-2 weeks) were used for the bioassays.

\subsection{Chemicals}

CTD was extracted and purified by a previously described method [42]. NCTD was purchased from Alfa Aesar (Haverhill, MA, purity > 98\%) (Table 1).

Table 1. Chemical structural formula and identifier of cantharidin and analogues.

Chemical Structural Formula $\quad$ Identifier

\subsection{Bioassays}

All the agents were dissolved in acetone. The volumes of $2.5 \mathrm{~mL}$ of CTD $(500 \mu \mathrm{g} / \mathrm{mL})$ and NCTD $(500 \mu \mathrm{g} / \mathrm{mL})$ dilutions were each dropped in $2 \mathrm{~g}$ of breadcrumbs and fully mixed together. These bread crumb mixtures were then transferred into $50 \mathrm{~mL}$ conical flasks. Control groups were prepared with the same volumes of acetone. These treated conical flasks were kept in a fume hood to evaporate the acetone. Then nymphs were introduced to each conical flask after the evaporation of acetone. Absorbent gauze was used to seal the conical flask mouth. These conical flasks containing nymphs were then transferred to the above-mentioned conditions $\left(27 \pm 2{ }^{\circ} \mathrm{C}, 65 \pm 5 \%\right.$ relative humidity with a photoperiod of 12:12 h (L:D)). Each treatment was conducted in triplicate. The nymphs were judged to be dead if they lacked any movement after using a fine brush to poke their feet. The mortality was corrected by Abbott's correction to ensure that the control morality remained lower than 15\% [43]. The agents which could be effective against $P$. americana were serially diluted to perform the bioassay to determine the $\mathrm{LC}_{50}$. The values of $\mathrm{LC}_{50}$ in this bioassay were calculated as Probits using SPSS 20.0 (IBM, Armonk, NY, USA)

\subsection{PSPs Activity and Inhibition Assay}

Enzyme preparation: The crude PSPs enzyme was prepared according to the Serine/Threonine Phosphatase Assay System protocol (Promega, Cat. \# V2460), with a slight modification. Ten nymphs were fully ground on ice in Tris-Hcl Buffer $(\mathrm{pH}=7.4$, containing $0.1 \% \beta$-mercaptoethanol, $1 \mathrm{mM}$ of EDTA, $1 \mathrm{mM}$ of PMSF, and $0.05 \%$ Triton-100). The homogenate was transferred into a $1.5 \mathrm{~mL}$ centrifuge tube and was centrifuged at $4{ }^{\circ} \mathrm{C}, 14,000 \mathrm{~g}$, for $30 \mathrm{~min}$. Then, $250 \mu \mathrm{L}$ of supernatant was added to the Sephadex G-25 spin column and centrifuged at $4{ }^{\circ} \mathrm{C}, 600 \mathrm{~g}$, for $5 \mathrm{~min}$. The PSPs crude enzyme would then be in the bottom of the spin column.

PSPs activity assay: The phosphate standard curve was made following the protocol of the Serine/Threonine Phosphatase Assay System. In brief, the $1 \mathrm{mM}$ phosphate standard solution was diluted with the supplied phosphate-free water into $50 \mu \mathrm{M}$. Different volumes $(0,2,4,10,20,40 \mu \mathrm{L})$ of diluted solution $(50 \mu \mathrm{M})$ were separately added to a 96-well flat plate. The wells which were not $40 \mu \mathrm{L}$ 
were supplied with phosphate-free water to achieve $40 \mu \mathrm{L}$. Then, $10 \mu \mathrm{L}$ of buffer (containing $250 \mathrm{mM}$ of imidazole, $1 \mathrm{mM}$ of EDTA, $0.1 \% \beta$-mercaptoethanol, $0.5 \mathrm{mg} / \mathrm{mL}$ of BSA, pH 7.2) was mixed with the $40 \mu \mathrm{L}$ of diluted solution. The reaction mixture was incubated at $30{ }^{\circ} \mathrm{C}$ for $10 \mathrm{~min}$. The reaction was stopped after the reaction mixture incubated with $50 \mu \mathrm{L}$ of molybdate dye/additive mixture at $30{ }^{\circ} \mathrm{C}$ for $30 \mathrm{~min}$. The absorbance of the samples was detected using an infinite M200 Microplate Reader (Tecan, Männedorf, Switzerland) at $600 \mathrm{~nm}$. The obtained absorbance data were exported into Excel 2018 to establish the standard curve. The PSPs activity was measured using the Serine/Threonine Phosphatase Assay System kit (Promega, Madison, WI, USA). Then, $30 \mu \mathrm{L}$ of phosphate-free water, $10 \mu \mathrm{L}$ of assay buffer (containing $250 \mathrm{mM}$ imidazole, $1 \mathrm{mM}$ EDTA, 0.1\% $\beta$-mercaptoethanol, $0.5 \mathrm{mg} / \mathrm{mL}$ BSA, pH 7.2), $5 \mu \mathrm{L}$ of $1 \mathrm{mM}$ phosphopeptide (RRA(pT)VA), and $5 \mu \mathrm{L}$ of PSPs enzyme were added into the 96-well plate. The reaction mixtures were then fully mixed and incubated at $30{ }^{\circ} \mathrm{C}$ for $30 \mathrm{~min}$. The reaction was terminated under the same conditions as described above. The absorbance at $600 \mathrm{~nm}$ (OD600) for each well was determined. Each assay was replicated three times. The amount of phosphate was calculated based on the phosphate standard curve.

Inhibition assay. The components of this measurement included $10 \mu \mathrm{g}$ of PSPs protein and gradient concentrations of CTD or NCTD $(100 \mathrm{nM}-100 \mu \mathrm{M})$ dissolved in dimethyl sulfoxide (DMSO). This mixture was incubated for $10 \mathrm{~min}$. Then, $25 \mu \mathrm{L}$ of phosphate-free water, $10 \mu \mathrm{L}$ of assay buffer, and $5 \mu \mathrm{L}$ of $1 \mathrm{mM}$ phosphopeptide (RRA (pT) VA) were added to the mixture. The reaction mixture was then incubated at $30{ }^{\circ} \mathrm{C}$ for $10 \mathrm{~min}$. The reaction was stopped as stated before. The OD 600 of the samples was recorded by the above-mentioned Microplate Reader. The control groups used DMSO to replace CTD or NCTD. Each assay was replicated three times.

The relative inhibition was calculated using the Formula (1):

$$
\text { Relative inhibition }(\%)=\frac{\text { OD600c }- \text { OD600t }}{\text { OD600c }} \times 100
$$

OD600c: the OD600 of the control group; OD600t: the variation OD600 of the treatment group. Data were plotted into the prism using the GraphPad prism 6.0 software (GraphPad Software, Inc., La Jolla, CA, USA) to determine the value of $\mathrm{IC}_{50}$.

\subsection{Molecular Cloning of P. americana pp5 (PaPP5)}

Total RNA was extracted by RNAiso Plus (TaKaRa, Dalian, China) utilizing the manufacturer's protocol. The concentration and the purity of extracted RNA was determined by NanoDrop-1000 (ThermoFisher, Waltham, MA, USA). First-strand cDNA was synthetized employing $1 \mu \mathrm{g}$ of RNA using the RevertAidTM First-Strand cDNA Synthesis Kit (ThermoFisher,) following the instructions of the manufacturer, and stored at $-20^{\circ} \mathrm{C}$. The known PP5 sequences of other insect species (Diuraphis noxia, GenBank: XP_015379688.1; Acyrthosiphon pisum, GenBank: XP_008181438.1; Anoplophora glabripennis, XP_018576896.1; Pediculus humanus corporis, XP_002425763.1; Epicauta chinensis, AHF45878.1, Halyomorpha halys XP_014290865.1, Tribolium castaneum XP_971407.1, Riptortus pedestris BAN20786.1; Cephus cinctus, XP_015610020.1; Diachasma alloeum, XP_015119779.1; Orussus abietinus, XP_012286908.1; Neodiprion lecontei, XP_015517121.1; Monomorium pharaonic, XP_012542571.1; Apis mellifera, XP_006567817.1; Pseudomyrmex gracilis, XP_020284073.1; Apis dorsata, XP_006613765.1; and Linepithema humile, XP_012231410.1) in NCBI GenBank were downloaded to design degenerate primers and amplify the conserved domain of PaPP5 (Table 2). The PCR process was operated on a $\mathrm{S} 1000^{\mathrm{TM}}$ thermal cycler (BioRad, Hercules, CA, USA). The amplified condition was followed by initial denaturation at $95^{\circ} \mathrm{C}$ for $30 \mathrm{~s}, 30$ cycles of denaturation at $95^{\circ} \mathrm{C}$ for $30 \mathrm{~s}$, annealing at $55^{\circ} \mathrm{C}$ for $30 \mathrm{~s}$ and extension at $72{ }^{\circ} \mathrm{C}$ for $1 \mathrm{~min}$, and with a final extension at $72{ }^{\circ} \mathrm{C}$ for $1 \mathrm{~min}$. Any amplification fragment was identified by $1 \%$ agarose gel. The amplification product was extracted and purified using a Biospin Gel Extraction Kit (Biospin, Beijing, China). The purified PCR product was cloned into pMD-19T vector (TaKaRa, Dalian, China) and sequenced for confirmation. The protocol of the SMARTTM RACE cDNA Amplification Kit (TaKaRa, Dalian, China) was followed to synthesize 3' and 
5'RACE templates and conduct the amplification reaction. By applying the specific primers to amplify the hypothetical full-length PaPP5, we then cloned the fragment into pMD-19T vector (TaKaRa) and sequenced it for confirmation (Table 2). The ORF finder (https://www.ncbi.nlm.nih.gov/orffinder/) was then applied to determine the open reading frame (ORF).

Table 2. Primers used in this study.

\begin{tabular}{llll}
\hline Gene & Primers & Sequence $\left(5^{\prime}-\mathbf{3}^{\prime}\right)$ & Usage \\
\hline PaPP5 & PaPP5D-F & CACATGTCCCTGGGCAAGTWYAARYTNGC & Degenerate primers \\
& PaPP5D-R & GGNAARTGYATCACCGTGTTCTCCGCC & Degenerate primers \\
PaPP5 & 5PaPP5-1 & TGGAACTTCTTGTGGGCGA & $5^{\prime}$ RACE \\
& 5PaPP5-2 & GAATAATATCCACGGTCAACA & $5^{\prime}$ RACE \\
& 3PaPP5-1 & GAAGGTGAAGTAAAGGCGAAG & $3^{\prime}$ RACE \\
& 3PaPP5-2 & GAAATAGGCAACCTCCAGAAG & $3^{\prime}$ RACE \\
PaPP5c & PaPP5c-F & CCCATATGCACCACCACCACCACCACTACAGCGGACCCAAGCTTG & Amplification of PaPP5c \\
PaPP5c & PaPP5c-R & CCCTCGAGTCACATCATTCCTAGCTGC & Xho1 \\
\hline
\end{tabular}

\subsection{Sequence Analysis of PaPP5}

The multiple alignment of amino acids was acquired by DNAMAN 7.0 software (Lynnon Biosoft, San Ramon, CA, USA). The deduced molecular weight (Mw) and isoelectric point (pI) of PaPP5 were predicted using ExPASy web tools (http://www.expasy.org/). The active site and the metal binding site of PaPP5 were determined using InterPro (http://www.ebi.ac.uk/interpro/).

\subsection{Recombinant PaPP5c Expression and Purification}

The catalytic domain of PP5 (167-489 amino acids, PP5c) was ligated to the pMD-19T vector. The PaPP5c-pMD-19T plasmid was digested at the Nde1 and Xho1 site and then inserted into pET-30a (+) (TaKaRa) vector (digested at the same restriction sites) with T4 ligase (ThermoFisher). The recombinant plasmid was transformed into E. coli BL21 (DE3) cells. The positive transformant was cultured in LB liquid medium including $50 \mathrm{mg} / \mathrm{mL}$ of kanamycin at $37^{\circ} \mathrm{C}$ with shaking at $200 \mathrm{rpm}$ until the OD600 reached 0.5 . We then added $0.1 \mathrm{mM}$ of IPTG and $1 \mathrm{mM}$ of $\mathrm{MnCl}_{2}$ to induce protein expression at $22^{\circ} \mathrm{C}$, with shaking at $200 \mathrm{rpm}$ for $24 \mathrm{~h}$. Recombinant cells were centrifuged at $4{ }^{\circ} \mathrm{C}, 8000 \mathrm{~g}$, for collecting the cell pellet. The harvested cell pellet was resuspended in PBS (10 mM), lysed with lysozyme $(1 \mathrm{mg} / \mathrm{mL})$, and then disrupted with sonication on ice for $10 \mathrm{~min}$. After sonication, the supernatant was subjected to protein purification. The supernatant was purified with a Ni-NTA column (Smart-Lifesciences, Changzhou, China) using gradient concentrations of imidazole buffer (50-250 $\mathrm{mM})$ to dissolve the protein. The purified protein was detected by $15 \%$ SDS-PAGE. Dialysate ( $4 \mathrm{mM}$ of $\mathrm{MnCl}_{2}, 10 \mathrm{mM}$ of Tris- $\mathrm{HCl}, \mathrm{pH} 8.0$ ) was employed to dialyze the protein overnight at $4{ }^{\circ} \mathrm{C}$. The concentration of purified protein was determined by the BCA method using the Easy II Protein Quantitative Kit (TransGene, Beijing, China).

\subsection{Enzyme Activity Assay}

The recombinant PaPP5c protein activity was measured in terms of DiFMUP as substrate (6,8-difluoro-4-methylumbelliferyl phosphate) with a slight modification [44]. The reaction mixture contained $1 \mu \mathrm{g}$ of recombinant PP5, $10 \mu \mathrm{L}$ of different concentrations of DiFMUP $(1,3,6,12,25$, 50 , and $100 \mu \mathrm{M}$ ), and $90 \mu \mathrm{L}$ of buffer (containing $30 \mathrm{mM}$ of HEPES, $0.1 \mathrm{mg} / \mathrm{mL}$ of BSA, $0.1 \mathrm{mM}$ of $\mathrm{MnCl}_{2}, 1 \mathrm{mM}$ of sodium ascorbate, $1 \mathrm{mM}$ of DTT, and $0.01 \%$ triton $\left.\mathrm{X}-100\right)$. The components of this reaction mixture were added into a black 96-well plate (ThermoFisher, USA) in sequence. The reaction mixture was incubated for $30 \mathrm{~min}$ at $30{ }^{\circ} \mathrm{C}$. Then, the fluorescence values were recorded using an Infinites 200 PRO multimode micro-plate reader (Tecan, Männedorf, Switzerland) (excitation at $360 \mathrm{~nm}$, emission at $450 \mathrm{~nm}$ ). The inactivated protein supplanted the enzyme as a control group. Data were plotted using GraphPad Prism 6.0 (GraphPad Software) to determine the enzyme kinetics with the Michaelis-Menten option. Each assay was replicated three times. 


\subsection{In Vitro Inhibition Assays on PP5c}

The test agents were dissolved in a $10 \mathrm{mg} / \mathrm{mL}$ stock solution with DMSO. The stock solution was diluted in gradient concentrations with water in later inhibition assays. Initially, $1 \mu \mathrm{g}$ of recombinant PP5c, $1 \mu \mathrm{L}$ of CTD or NCTD, and $100 \mu \mathrm{L}$ of reaction buffer ( $30 \mathrm{mM}$ of HEPES, $0.1 \mathrm{mg} / \mathrm{mL}$ of BSA, $0.1 \mathrm{mM}$ of $\mathrm{MnCl}_{2}, 1 \mathrm{mM}$ of sodium ascorbate, $1 \mathrm{mM}$ of DTT, $0.01 \%$ triton X-100) were incubated for $10 \mathrm{~min}$ at $30{ }^{\circ} \mathrm{C}$. Afterwards, $10 \mu \mathrm{L}$ of DiFMUP $(100 \mu \mathrm{M})$ was added into the reaction mixture for incubation for $30 \mathrm{~min}$ at $30{ }^{\circ} \mathrm{C}$. The reaction was stopped by adding $100 \mu \mathrm{L}$ of $300 \mathrm{mM}$ phosphate (pH 10). The inactivated protein replaced the enzyme as a negative control group. Meanwhile, the positive control group used DMSO in place of the recombinant protein. Each assay was replicated five times. The fluorescence values for the inhibition assay are the same as with the enzyme activity assay.

Relative inhibition was calculated using the Formula (2):

$$
\text { Relative inhibition }(\%)=\frac{\operatorname{control}(\mathrm{Fv})-\text { treatment }(\mathrm{Fv})}{\operatorname{control}(\mathrm{Fv})} \times 100
$$

Control (Fv): the fluorescence value of the control group; treatment $(\mathrm{Fv})$ : the fluorescence value of the treatment group. Data were plotted into prism using the GraphPad prism 6.0 software (GraphPad) to determine the value of $\mathrm{IC}_{50}$.

\section{Results}

\subsection{Toxicity of CTD and Analogues on P. americana}

Under the primary screening concentration of $500 \mu \mathrm{g} / \mathrm{mL}, \mathrm{CTD}$ resulted in a $100 \%$ mortality rate. The mortality rate from NCTD was far below that for CTD. The mortality rate caused by NCTD was $13.33 \%$. (Table 3). The results of toxicity regression equations show that CTD caused the most significant toxicity, and the $\mathrm{LC}_{50}$ was $50.92 \mu \mathrm{g} / \mathrm{mL}$ for $\mathrm{LC}_{50}$ (Table 4).

Table 3. Toxicity of cantharidin and its analogue to P. americana at $500 \mu \mathrm{g} / \mathrm{mL}$.

\begin{tabular}{cc}
\hline Identifier & Mortality Rate (\%) \\
\hline Cantharidin & 100 \\
Norcantharidin & 13.33 \\
\hline
\end{tabular}

Table 4. Toxicity determination of effective compounds on P. americana ( $48 \mathrm{~h})$.

\begin{tabular}{ccccc}
\hline Identifier & Toxicity Regression Equations & LC $_{\mathbf{5 0}}(\boldsymbol{\mu} \mathbf{g} / \mathbf{m L})$ & $\chi^{\mathbf{2}}$ & $\mathbf{9 5 \%}$ Confidence Interval \\
\hline Cantharidin & $\mathrm{Y}=-5.611+3.326 \mathrm{X}$ & 50.920 & 1.998 & $19.204-82.211$ \\
\hline
\end{tabular}

\subsection{Inhibition Effects of CTD and NCTD on PSP of P. americana}

An in vitro inhibition assay of CTD and NCTD on the crude PSP of P. americana displayed CTD, and NCTD had inhibitory effects on PSP, whereas the differences in the values of IC $_{50}$ were obvious. The inhibition effect of CTD was superior to that of NCTD. The $\mathrm{IC}_{50}$ of CTD was $7.21 \pm 0.94 \mu \mathrm{M}$, whereas the value of NCTD $(31.65 \pm 3.87 \mu \mathrm{M})$ was over four times that of CTD (Figure 1). 

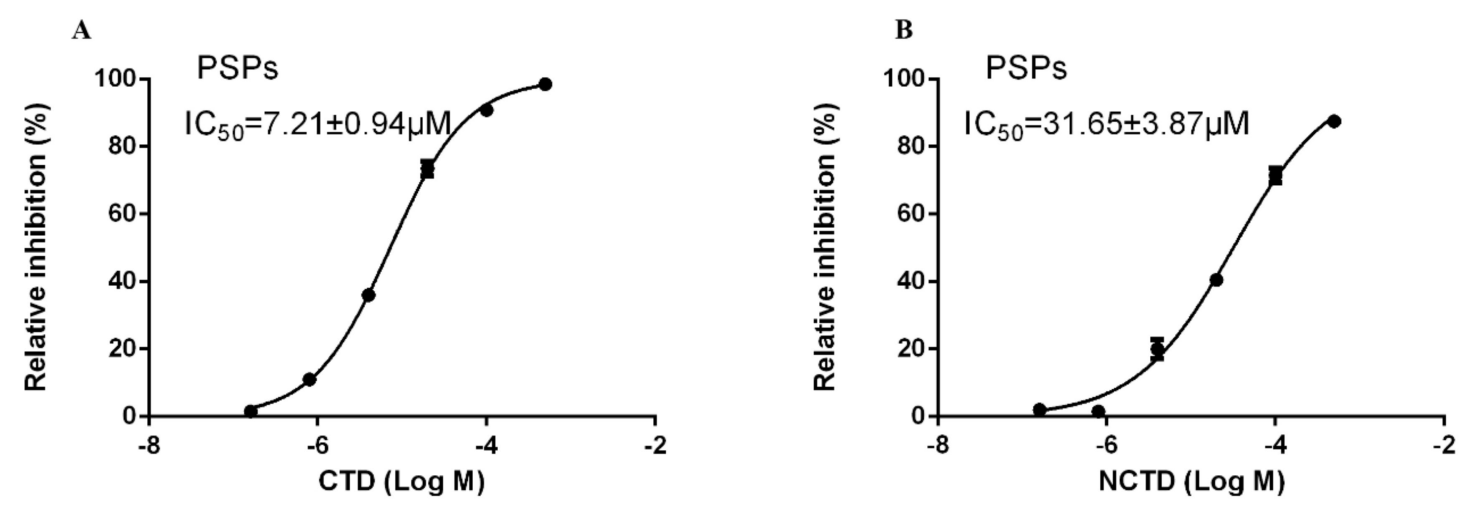

Figure 1. Inhibition curves of Cantharidinand Norcantharidin on the serine/threonine protein phosphatase (PSPs) of P. americana. Data are shown as mean \pm SD. (A) Cantharidin, (B) Norcantharidin.

\subsection{Characterization of PaPP5 Sequence}

We cloned the full-length cDNA of PaPP5 and uploaded the amino acids sequence of ORF to GenBank. The obtained accession number was AZT88974.1. Multiple alignment shows that PaPP5 shares an $80.81 \%$ identity with the compared PP5 of different insect species. The deduced full-length ORF sequence of PaPP5 encoded 489 amino acids. The predicted theoretical molecular weight (Mw) and isoelectric point (pI) were 55.82 KDa and 6.18, respectively. Additionally, the predication based on the obtained PaPP5 sequence displays that the predicted catalytic domain of PaPP5 (PP5c) consists of the 167-482 residues and the TPR (tetratricopeptide repeat) are from 19-52, 53-86, and 87-120 amino acids (Figure 2). The deduced molecular weight of PaPP5c was $36.09 \mathrm{KDa}$. The three conserved motifs (-GDXHG-, -GDXVDRG- and -GNHE-) of the PSPs catalytic domain in PaPP5 were GDIHG, GDFVDRG and GNHE.

\subsection{The Recombinant PaPP5c}

The N-terminal region of PP5 has an autoinhibitory function and thus inhibits the catalytic activity [45]. Therefore, we expressed PP5c in vitro. SDS-PAGE showed that we obtained the fusion recombinant PP5c, which was consistent with the predicated molecular weight (36.89 kDa) calculated from the deduced amino acid sequence of PaPP5c with His-tag in pET-30a (Figure 3). The concentration of recombinant PaPP5c was $0.5 \mu \mathrm{g} / \mu \mathrm{L}$. According to the Michaelis-Menten plot, the $\mathrm{k}_{\mathrm{m}}$ was $144.10 \pm 9.730 \mu \mathrm{M}$ and the $\mathrm{V}_{\max }$ of the recombinant PP5c was $657,285 \pm 24,078 \mathrm{mRF} / \mathrm{min}$, respectively (Figure 4).

\subsection{Inhibition Effects of CTD and NCTD on PaPP5c}

We determined the inhibition effects of CTD and NCTD on PaPP5c. The results show that CTD has a more significant inhibition effect on PaPP5c compared to NCTD. The $\mathrm{IC}_{50}$ of CTD on PaPP5c is $0.39 \pm 0.04 \mu \mathrm{M}$. NCTD was inferior to CTD, resulting in an $\mathrm{IC}_{50}$ of $1.87 \pm 0.23 \mu \mathrm{M}$ (Figure 5). 


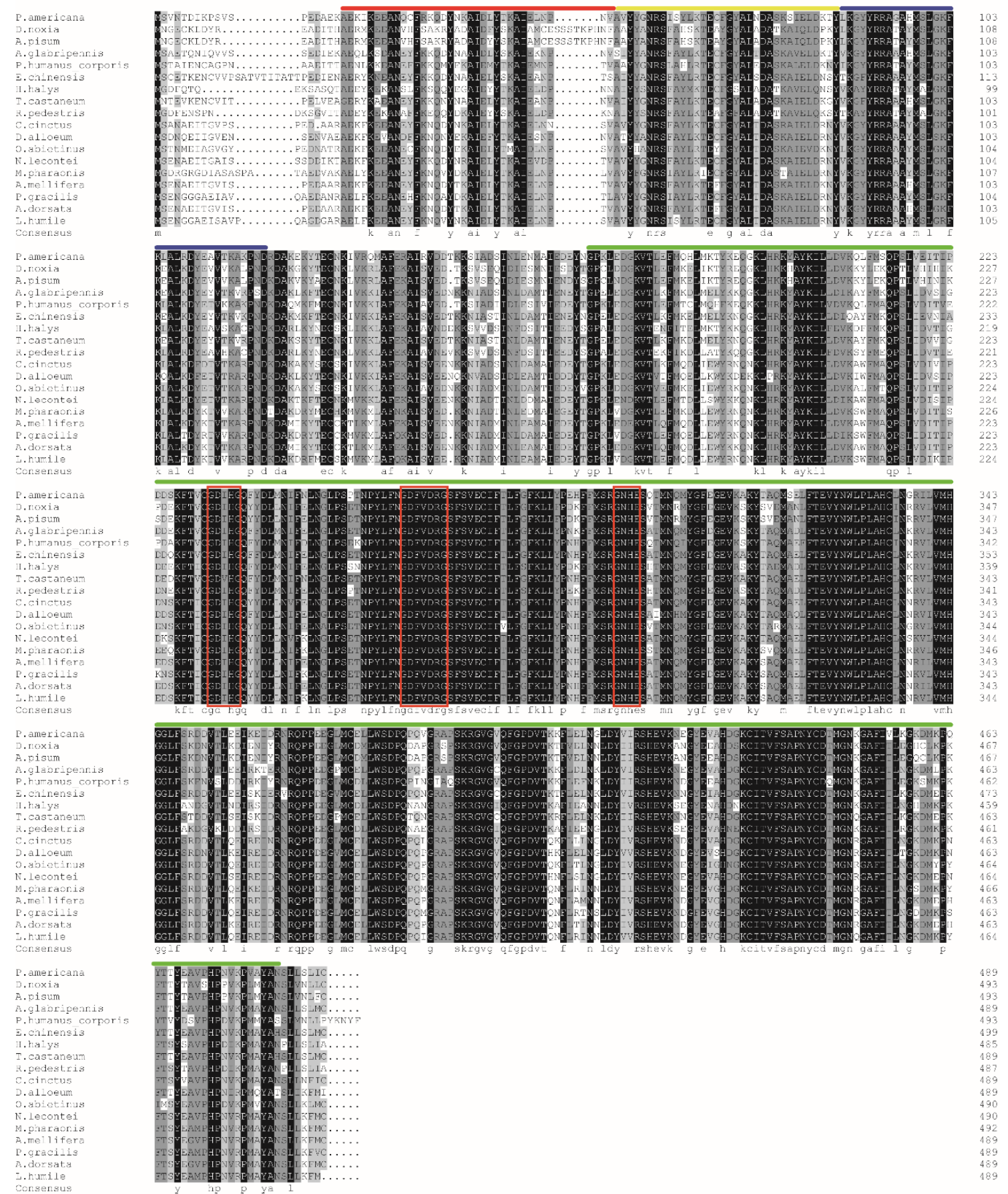

Figure 2. Multiple alignments of the deduced amino acid sequences of PP5 from P. americana and with other insect species ((D. noxia, GenBank: XP_015379688.1; A. pisum, GenBank: XP_008181438.1; A. glabripennis, XP_018576896.1; P. humanus corporis, XP_002425763.1; E. chinensis, AHF45878.1, H. halys XP_014290865.1, T. castaneum XP_971407.1, R. pedestris BAN20786.1; C. cinctus, XP_015610020.1; D. alloeum, XP_015119779.1; O. abietinus, XP_012286908.1; N. lecontei, XP_015517121.1; M. pharaonic, XP_012542571.1; A. mellifera, XP_006567817.1; P. gracilis, XP_020284073.1; A. dorsata, XP_006613765.1; L. humile, XP_012231410.1). The TPR domains are shown in red, yellow, and blue lines. The predicted catalytic domain of PaPP5 (PP5c) is indicated by a green line. The three conserved motifs (-GDXHG-, -GDXVDRG-, and -GNHE-) are presented in a red horizontal rectangle. 


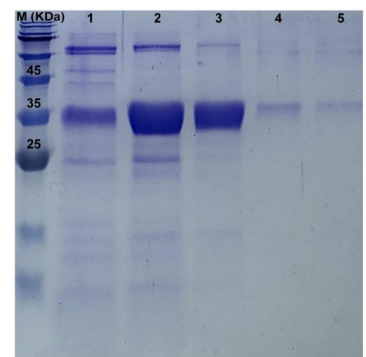

Figure 3. Analysis of the recombinant PaPP5c by 15\% SDS-PAGE. M: protein marker; Lane 1: $50 \mathrm{mM}$ imidazole elution; Lane 2: $100 \mathrm{mM}$ imidazole elution; Lane 3: $150 \mathrm{mM}$ imidazole elution; Lane 4: 200 mM imidazole elution; Lane 5: 250 mM imidazole elution.

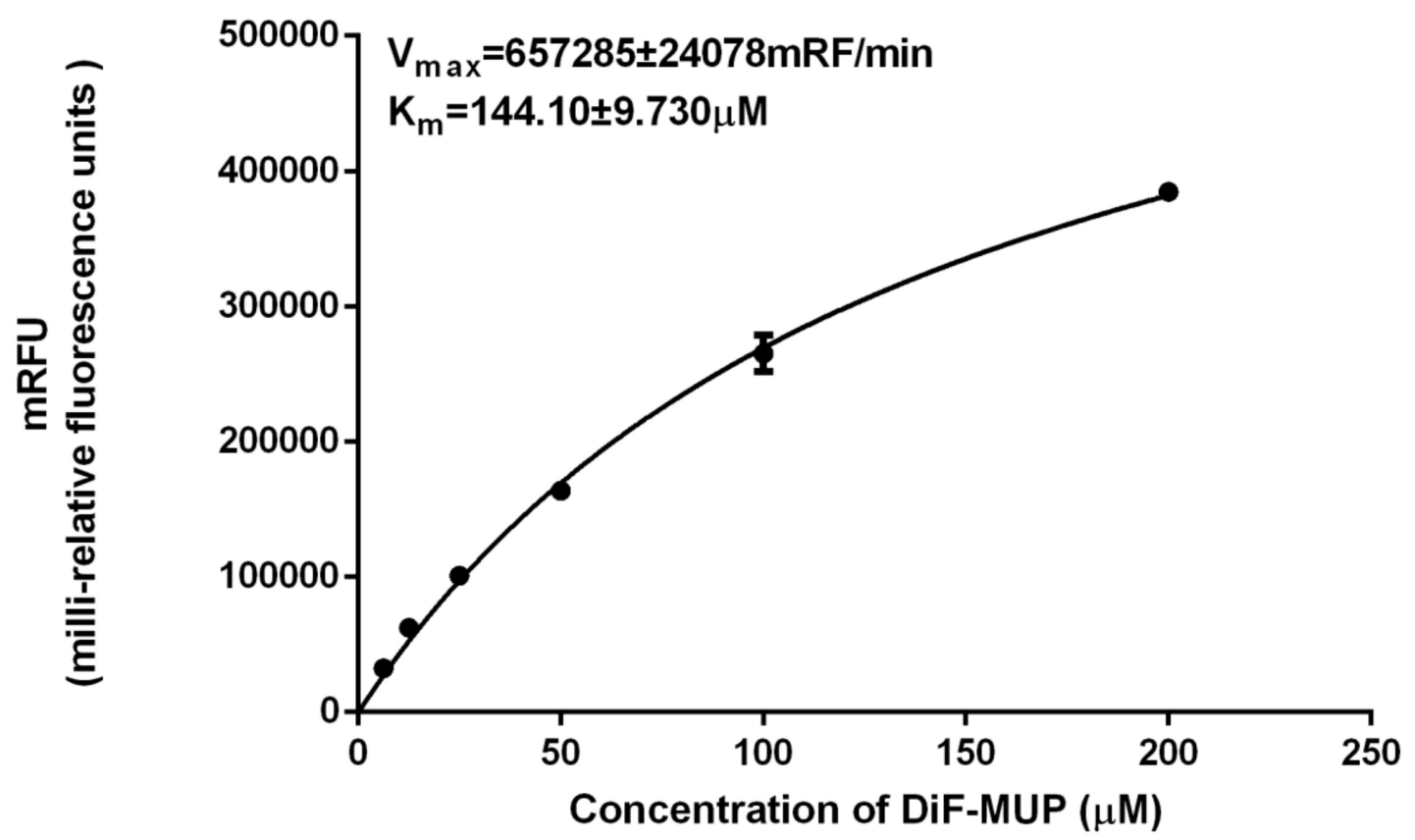

Figure 4. Kinetics of DiFMUP (6,8-difluoro-4-methylumbelliferyl phosphate) dephosphorylation by the catalytic domain of PP5 (PP5c). Data are shown as mean \pm SD.

A

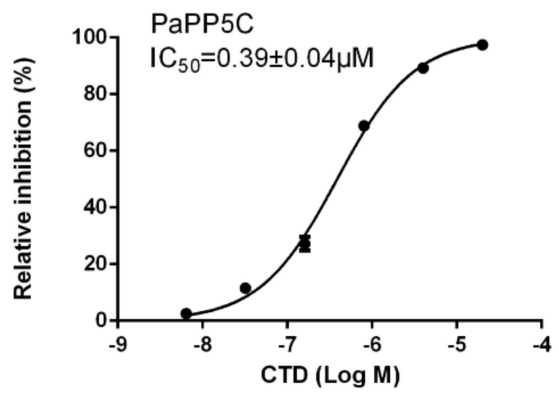

B

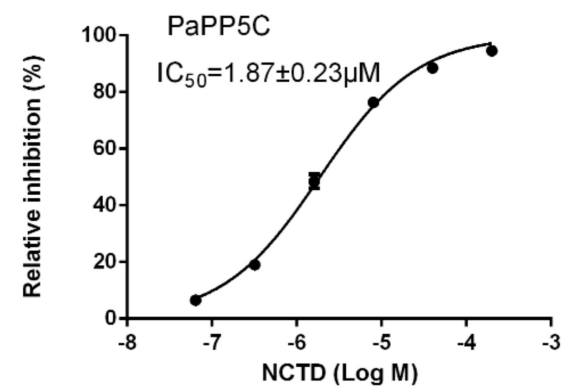

Figure 5. Inhibition curves of Cantharidin and Norcantharidin on the catalytic domain of PP5 (PP5c). Data are shown as mean \pm SD. (A) Cantharidin, (B) Norcantharidin.

\section{Discussion}

Currently, insecticide resistance remains one of the barriers for agricultural production and public health pest management. Therefore, the development of novel insecticides is needed. CTD has been previously reported to have insecticidal activity in a broad range of pests [29]. However, CTD has 
not been widely applied in the field due to the high cost of acquisition. In this study, we determined the ingestion toxicity of CTD and its derivative NCTD on P. americana. The results illustrate that CTD displays a significant toxicity against $P$. americana. This agrees with a previous report documenting how CTD had significant insecticidal activity against many pests [29]. In addition, this study demonstrates that it has a similar toxicity against P. americana. Meanwhile, this result also suggests that CTD may have the potential to be effective against a broader range of pests. Additionally, although previous studies have reported that NCTD shows an excellent toxicity on P. xylostella, it did not show any significant toxicity on P. americana. We infer that this difference probably results from either different feeding or the presence of different penetration and metabolic characteristics between different species. Although both CTD and NCTD showed strong inhibitory effects on PSPs, their toxicity against P. American displayed huge differences. This may due to the inhibition on PSPs is not the sole mechanism for toxicity. Additionally, the huge disparity in toxicity between NCTD and CTD may result from differences in the structure. The changes in structure may alter the metabolic pathway of $P$. americana towards NCTD. Furthermore, some gut microorganisms may be involved in the detoxification of NCTD.

Previous research has demonstrated that CTD can inhibit PSPs [34]. To verify the effects of the CTD and NCTD on PSPs in P. americana, we conducted inhibition assays on PSPs in vitro. In vitro inhibition assays indicate that the activity of PSPs is significantly inhibited by CTD and NCTD. As reported, CTD can effectively inhibit the activity of PSPs in plants such as Arabidopsis thaliana $\left(\mathrm{IC}_{50}=0.63 \mu \mathrm{M}\right)$ [33]. It also has been reported that CTD can inhibit the activity of PSP $\mathrm{S}$ in P. xylostella $\left(\mathrm{IC}_{50}=5.39 \mu \mathrm{M}\right)$ [36]. In this study, the value of $\mathrm{IC}_{50}$ of CTD on PSPs was $7.21 \mu \mathrm{M}$, which is comparable to the above-mentioned values of $\mathrm{IC}_{50}$. This indicates that CTD has a strong inhibition effect on PSPs in P. americana. Information on the analogue of CTD on PSPs of insects is little known. In the present study, NCTD showed inhibition effects on PSPs, indicating that their potential inhibition capacity can be comparable to that of CTD. Our results show that CTD and NCTD have the capacity to inhibit the activity of PSPs in P. americana. These results indicate that CTD and NCTD have strong inhibition effects on the PSP family of proteins of P. americana. However, it is not clear which specific PSPs in P. americana have their activity inhibited by CTD and NCTD.

The PSPs protein family encompasses a large number of members, including PP1, PP2A, PP2B, PP4, PP5, PP6, and PP7 [46]. In our previous study, we evaluated the binding mode of the interaction between the PxPP5 of P. xylostella and CTD, indicating that CTD had a strong binding affinity towards PP5 [36]. Therefore, we propose that the toxicity of CTD and its analogues against P. americana is also due to their inhibition effects on PP5. It has been reported that PP5 is comprised of an N-terminal tetratricopeptide repeat (TPR) and a C-terminal region [47]. The catalytic domain of PP5 (PP5c) is highly conserved and shares a consensus sequence (-GDXHG-, -GDXVDRG-, and -GNHE-) with other PSP members [34]. Here, we cloned the PP5 of P. americana. The sequence analysis shows that PaPP5 shares a highly conserved TPR and catalytic domain (PP5c), which is consistent with earlier reports of the characteristics of the PP5 structure. Furthermore, we obtained the fusion recombinant PaPP5c via prokaryotic expression, suggesting that the expression conditions for PaPP5c are suitable in this study. Additionally, previous reports on the kinetics of Human PP5c are as follows: Km: $141 \pm 10.7 \mu \mathrm{M}$; Vmax: 216,9730 $\pm 49,180 \mathrm{mRFU} / \mathrm{min}$ [43]. The results of the kinetics of recombinant PaPP5c demonstrate that the recombinant PaPP5c were comparable to the previously reported result, and thus the obtained purified recombinant PaPP5c could perform the following tests. According to a previous report, the $\mathrm{IC}_{50}$ of CTD on human PP5c can reach $0.2 \mu \mathrm{M}$ [48]. In this study, the values of the $\mathrm{IC}_{50}$ of $\mathrm{CTD}$ and NCTD on PaPP5c also reached 0.39 and $1.87 \mu \mathrm{M}$, respectively, showing an inhibitory effect on PaPP5c. Additionally, the results of the inhibition assay on PP5c further support the bioassay results. CTD shows the most significant inhibition rates on PP5c, and this result corresponds to the bioassay showing that CTD induced the most ingestion toxicity on P. americana. While the inhibition rate of NCTD on PaPP5c is obviously inferior to that of CTD, its results in the bioassay are far inferior to those of CTD. As reported, PP5 is involved in cellular survival and death. Meanwhile, PP5 is vital for regulating signaling, which regulates a series of physical functions such as metabolism [49]. Because of 
the strong inhibition effects of CTD on PaPP5c, the metabolism may be disrupted. Therefore, we infer that the toxicity of CTD on P. americana is likely due to its inhibition effect on PP5c. Although NCTD did not show significant toxicity against $P$. americana, it suggested that the CTD derivatives which have a structure like that of NCTD may not compare to CTD. However, considering that CTD showed an excellent toxicity against $P$. americana, it can be inferred that other derivatives of CTD which do not have an NCTD-like structure may have a similar bioactivity to that of CTD. In this way, the development of CTD derivatives is of significance.

\section{Conclusions}

Overall, the above findings demonstrate that CTD has insecticidal activity against $P$. americana. The inhibition effect of CTD on PaPP5c may be responsible for the toxicity of CTD towards P. americana. This study promotes CTD as a potential agent to control P. americana, and this may contribute to the development of CTD derivatives for deterring pests. In addition, considering how PP5 is affected by CTD and its analogue, we speculate that PP5 may be a novel target for future insecticide development.

Author Contributions: Y.Z. conceived the research; H.S., Y.L., and X.L. performed the experiments; H.S., Y.L., and X.L. analyzed the data; H.S. and Y.L. wrote the manuscript. All authors have read and agreed to the published version of the manuscript.

Funding: This research was funded by the National Natural Science Foundation of China (31872012).

Acknowledgments: We are grateful to J.R. Schrock (Emporia State University, USA) for revising the manuscript. Conflicts of Interest: The authors declare no conflict of interest.

\section{References}

1. Zhang, X.C.; Zhang, F. The potential control strategies based on the interaction between indoor cockroaches and their symbionts in China. In Advances in Insect Physiology; Elsevier: Cambridge, MA, USA, 2018; Volume 55, pp. 55-122.

2. Ejimadu, L.; Goselle, O.; Ahmadu, Y.; James-Rugu, N. Specialization of Periplaneta americana (American cockroach) and Blattella germanica (German cockroach) towards intestinal parasites: A public health concern. IOSR-JPBSIOSR 2015, 10, 23-32.

3. Mille, P.; Peters, B. Overview of the public health implications of cockroaches and their management. N. S. W. Public Health Bull. 2004, 15, 208-211.

4. Zahraei-Ramazani, A.R.; Saghafipour, A.; Vatandoost, H. Control of American cockroach (Periplaneta americana) in municipal sewage disposal system, Central Iran. J. Arthropod. Borne Dis. 2018, 12, 172. [CrossRef] [PubMed]

5. Bell, W.J.; Adiyodi, K. The American Cockroach; Springer Science \& Business Media: New York, NY, USA, 1982.

6. Manzoor, F.; Munir, N.; Ambreen, A.; Naz, S. Efficacy of some essential oils against American cockroach Periplaneta americana (L.). J. Med. Plants Res. 2012, 6, 1065-1069.

7. Kass, D.; McKelvey, W.; Carlton, E.; Hernandez, M.; Chew, G.; Nagle, S.; Garfinkel, R.; Clarke, B.; Tiven, J.; Espino, C.; et al. Effectiveness of an integrated pest management intervention in controlling cockroaches, mice, and allergens in New York City public housing. Environ. Health Perspect. 2009, 117, 1219-1225. [CrossRef] [PubMed]

8. Ngoh, S.P.; Choo, L.E.W.; Pang, F.Y.; Huang, Y.; Kini, M.R.; Ho, S.H. Insecticidal and repellent properties of nine volatile constituents of essential oils against the American cockroach, Periplaneta americana (L.). Pestic. Sci. 1998, 54, 261-268. [CrossRef]

9. Rahimian, A.A.; Hanafi-Bojd, A.A.; Vatandoost, H.; Zaim, M. A review on the insecticide resistance of three species of cockroaches (Blattodea: Blattidae) in Iran. J. Econ. Entomol. 2019, 112, 1-10. [CrossRef]

10. World Health Organization (WHO). Pesticides and Their Application: For the Control of Vectors and Pests of Public Health Importance; World Health Organization: Geneva, Switzerland, 2006.

11. Pai, H.H.; Hsu, E.L.; Wu, S.C.; Lin, K.C. Study on the resistance of Blattella germanica and Periplaneta americana to insecticides in Taiwan. Chin. J. Hyg. Insect Equip. 2017, 23, 13-17. 
12. Wu, D.X.; Scharf, M.E.; Neal, J.J.; Suiter, D.R.; Bennett, G.W. Mechanisms of fenvalerate resistance in the German cockroach, Blattella germanica (L.). Pestic. Biochem. Physiol. 1998, 61, 53-62. [CrossRef]

13. Copping, L.G.; Menn, J.J. Biopesticides: A review of their action, applications and efficacy. Pest. Manag. Sci. 2000, 56, 651-676. [CrossRef]

14. Villaverde, J.J.; Sevilla-Moran, B.; Sandin-Espana, P.; Lopez-Goti, C.; Alonso-Prados, J.L. Biopesticides in the framework of the European Pesticide Regulation (EC) No. 1107/2009. Pest. Manag. Sci. 2014, 70, 2-5. [CrossRef] [PubMed]

15. Chaaban, A.; Richardi, V.S.; Carrer, A.R.; Brum, J.S.; Cipriano, R.R.; Martins, C.E.N.; Silva, M.A.N.; Deschamps, C.; Molento, M.B. Insecticide activity of Curcuma longa (leaves) essential oil and its major compound $\alpha$-phellandrene against Lucilia cuprina larvae (Diptera: Calliphoridae): Histological and ultrastructural biomarkers assessment. Pestic. Biochem. Physiol. 2019, 153, 17-27. [CrossRef] [PubMed]

16. Pavela, R.; Maggi, F.; Petrelli, R.; Cappellacci, L.; Buccioni, M.; Palmieri, A.; Canale, A.; Benelli, G. Outstanding insecticidal activity and sublethal effects of Carlina acaulis root essential oil on the housefly, Musca domestica, with insights on its toxicity on human cells. Food Chem. Toxicol. 2020, 136, 111037. [CrossRef] [PubMed]

17. Rezaei, M.; Khaghani, R.; Moharramipour, S. Insecticidal activity of Artemisia sieberi, Eucalyptus camaldulensis, Thymus persicus and Eruca sativa oils against German cockroach, Blattella germanica (L.). J. Asia Pac. Entomol. 2019, 22, 1090-1097. [CrossRef]

18. Sittichok, S.; Phaysa, W.; Soonwera, M. Repellency activity of essential oil on thai local plants against American cockroach (Periplaneta americana L.; Blattidae: Blattodea). Int. J. Agric. Technol. 2013, 9, 1613-1620.

19. Gutierrez, A.C.; Machado, J.; Hubner-Campos, R.; Pennisi, M.; Rodrigues, J.; Lopez Lastra, C.C.; Garcia, J.J.; Fernandes, É.K.; Luz, C. New insights into the infection of the American cockroach Periplaneta americana nymphs with Metarhizium anisopliae s.l. (Ascomycota: Hypocreales). J. Appl. Microbiol. 2016, 121, 1373-1383. [CrossRef] [PubMed]

20. Hubner-Campos, R.F.; Leles, R.N.; Rodrigues, J.; Luz, C. Efficacy of entomopathogenic hypocrealean fungi against Periplaneta americana. Parasitol. Int. 2013, 62, 517-521. [CrossRef]

21. Carrel, J.E.; McCairel, M.H.; Slagle, A.J.; Doom, J.P.; Brill, J.; McCormick, J.P. Cantharidin production in a blister beetle. Experientia 1993, 49, 171-174. [CrossRef]

22. Jiang, M.; Lu, S.M.; Qi, Z.Y.; Zhang, Y.L. Characterized cantharidin distribution and related gene expression patterns in tissues of blister beetles, Epicauta chinensis. Insect Sci. 2019, 26, 240-250. [CrossRef]

23. Carrel, J.E.; Eisner, T. Cantharidin: Potent feeding deterrent to insects. Science 1974, 183, 755-757. [CrossRef]

24. Huang, Z.; Zhang, Y. Chronic sublethal effects of cantharidin on the diamondback moth Plutella xylostella (Lepidoptera: Plutellidae). Toxins 2015, 7, 1962-1978. [CrossRef] [PubMed]

25. Khan, R.A.; Liu, J.Y.; Rashid, M.; Wang, D.; Zhang, Y.L. Cantharidin impedes activity of glutathione S-transferase in the midgut of Helicoverpa armigera Hubner. Int. J. Mol. Sci. 2013, 14, 5482-5500. [CrossRef] [PubMed]

26. Rashid, M.; Khan, R.A.; Zhang, Y. Physiological and population responses of armyworm Mythimna separata (Lepidoptera: Noctuidae) to a sublethal dose of cantharidin-AC. J. Econ. Entomol. 2013, 106, 2177-2182. [CrossRef] [PubMed]

27. Wu, Z.W.; Yang, X.Q.; Zhang, Y.L. The toxicology and biochemical characterization of cantharidin on Cydia pomonella. J. Econ. Entomol. 2015, 108, 237-244. [CrossRef] [PubMed]

28. Khan, R.A.; Rashid, M.; Wang, D.; Zhang, Y.L. Lethal and sublethal effects of cantharidin on the life history traits and population parameters of Helicoverpa armigera (Hubner) (Lepidoptera: Noctuidae). Pest. Manag. Sci. 2014, 70, 39-45. [CrossRef] [PubMed]

29. Li, Y.F.; Sun, H.; Xi, N.; Zhang, Y. Effects of cantharidin and norcantharidin on larval feeding and adult oviposition preferences of the diamondback moth (Lepidoptera: Plutellidae). J. Econ. Entomol. 2019, 112, 1634-1637. [CrossRef]

30. Yasoob, H.; Ali Khan, H.A.; Zhang, Y. Toxicity and sublethal effects of cantharidin on Musca domestica (Diptera: Muscidae). J. Econ. Entomol. 2017, 110, 2539-2544. [CrossRef]

31. Cao, W.D.; Zhang, Z.Y.; Yang, B.D.; Zhang, M.Z.; Sun, S.L. Inhibition of cantharidin and demethylcantharidin to seven phytopathogenic fungi. Acta Phytophylacica Sinica 2008, 35, 63-68.

32. Honkanen, R.E. Cantharidin, another natural toxin that inhibits the activity of serine threonine protein phosphatases Type-1 and Type-2a. FEBS Lett. 1993, 330, 283-286. [CrossRef] 
33. Bajsa, J.; Pan, Z.; Duke, S.O. Transcriptional responses to cantharidin, a protein phosphatase inhibitor, in Arabidopsis thaliana reveal the involvement of multiple signal transduction pathways. Physiol. Plant. 2011, 143, 188-205. [CrossRef]

34. Bertini, I.; Calderone, V.; Fragai, M.; Luchinat, C.; Talluri, E. Structural basis of serine/threonine phosphatase inhibition by the archetypal small molecules cantharidin and norcantharidin. J. Med. Chem. 2009, 52, 4838-4843. [CrossRef] [PubMed]

35. Prickett, T.D.; Brautigan, D.L. The $\alpha 4$ regulatory subunit exerts opposing allosteric effects on protein phosphatases PP6 and PP2A. J. Biol. Chem. 2006, 281, 30503-30511. [CrossRef] [PubMed]

36. Chen, X.; Liu, J.; Zhang, Y. Cantharidin impedes the activity of protein serine/threonine phosphatase in Plutella xylostella. Mol. Biosyst. 2014, 10, 240-250. [CrossRef] [PubMed]

37. Liu, J.Y.; Chen, X.E.; Zhang, Y.L. Insights into the key interactions between human protein phosphatase 5 and cantharidin using molecular dynamics and site-directed mutagenesis bioassays. Sci. Rep. 2015, 5, 12359. [CrossRef]

38. Wang, G.S. Medical uses of Mylabris in ancient China and recent studies. J. Ethnopharmacol. 1989, 26, 147-162. [CrossRef]

39. Dauben, W.G.; Kessel, C.R.; Takemura, K.H. Simple, efficient total synthesis of cantharidin via a high-pressure Diels-Alder reaction. J. Am. Chem. Soc. 1980, 102, 6893-6894. [CrossRef]

40. Bajsa, J.; Duke, S.O.; Tekwani, B.L. Plasmodium falciparum serine/threonine phoshoprotein phosphatases (PPP): From housekeeper to the 'holy grail'. Curr. Drug Targets 2008, 9, 997-1012. [CrossRef]

41. Zeng, L.; Liu, Y.; Pan, J.; Liu, X. Formulation and evaluation of norcanthridin nanoemulsions against the Plutella xylostella (Lepidotera: Plutellidae). BMC Biotechnol. 2019, 19, 16. [CrossRef]

42. Carrel, J.E.; Doom, J.P.; McCormick, J.P. Quantitative determination of cantharidin in biological materials using capillary gas chromatography with flame ionization detection. J. Chromatogr. 1985, 342, 411-415. [CrossRef]

43. Abbott, W.S. A method of computing the effectiveness of an insecticide. J. Am. Mosq. Control. Assoc. 1987, 3, 302-303. [CrossRef]

44. Ni, L.; Swingle, M.S.; Bourgeois, A.C.; Honkanen, R.E. High yield expression of serine/threonine protein phosphatase type 5, and a fluorescent assay suitable for use in the detection of catalytic inhibitors. Assay Drug Dev. Technol. 2007, 5, 645-653. [CrossRef] [PubMed]

45. Cher, C.; Tremblay, M.H.; Barber, J.R.; Chung Ng, S.; Zhang, B. Identification of chaulmoogric acid as a small molecule activator of protein phosphatase 5. Appl. Biochem. Biotechnol. 2010, 160, 1450-1459. [CrossRef] [PubMed]

46. Brautigan, D.L.; Shenolikar, S. Protein serine/threonine phosphatases: Keys to unlocking regulators and substrates. Annu. Rev. Biochem. 2018, 87, 921-964. [CrossRef] [PubMed]

47. Peti, W.; Nairn, A.C.; Page, R. Structural basis for protein phosphatase 1 regulation and specificity. FEBS J. 2013, 280, 596-611. [CrossRef] [PubMed]

48. Chattopadhyay, D.; Swingle, M.R.; Salter, E.A.; Wood, E.; D'Arcy, B.; Zivanov, C.; Abney, K.; Musiyenko, A.; Rusin, S.F.; Kettenbach, A.; et al. Crystal structures and mutagenesis of PPP-family ser/thr protein phosphatases elucidate the selectivity of cantharidin and novel norcantharidin-based inhibitors of PP5C. Biochem. Pharmacol. 2016, 109, 14-26. [CrossRef] [PubMed]

49. Shi, Y. Serine/threonine phosphatases: Mechanism through structure. Cell 2009, 139, 468-484. [CrossRef] [PubMed]

(C) 2020 by the authors. Licensee MDPI, Basel, Switzerland. This article is an open access article distributed under the terms and conditions of the Creative Commons Attribution (CC BY) license (http://creativecommons.org/licenses/by/4.0/). 